\title{
LA ASISTENCIA TÉCNICA Y EL COMPROMISO CON EL MEDIO DESDE EL CENTRO DE ESTUDIOS HISTÓRICOS ARQUITECTÓNICOS Y URBANOS. EL CASO DE LA PLAZA J.B. CABRAL Y EL MUNICIPIO DE LA CIUDAD DE CORRIENTES
}

\section{TECHNICAL SUPPORT AND COMMITMENT TO THE ENVIRONMENT AT THE CENTER FOR URBAN AND ARCHITECTURAL STUDIES. CASE STUDY: J.B. CABRAL SQUARE AND CORRIENTES CITY MUNICIPALITY}

\section{SÁNCHEZ NEGRETTE, Ángela / LANCELLE , Anna}

Sánchez Negrette, Ángela Dra. Arq. Ángela Sánchez Negrette/ Directora CEHAU - FAU - UNNE/ Investigadora CONICET/ Prof. Tit. Cátedra Historia y Crítica II - FAU - UNNE. E-mail: asancheznegrette@gmail.com

Lancelle, Anna Mgter. Arq. Anna Lancelle/ Co-Directora CEHAU - FAU - UNNE/ Docente Investigadora SGCyT/ Prof. Adj. Cátedras Historia y crítica I y || - FAU - UNNE. E-mail: annalancelle@yahoo.com.ar

Palabras Clave: Patrimonio - Salvaguarda - Arqueología Urbana

Keywords: Heritage - Safekeeping - Urban Archeology.

\section{RESUMEN}

El Centro de Estudios Históricos Arquitectónicos y Urbanos CEHAU realiza en forma permanente, estudios e investigaciones sobre las diferentes ciudades de la región y acerca de la evolución de la arquitectura local.

Ante hallazgos de construcciones subterráneas durante el proceso de remodelación de la Plaza J. B. Cabral de la ciudad de Corrientes, el Municipio decidió solicitar al CEHAU su intervención a fin de realizar los estudios pertinentes, lo que se realizó con amplia divulgación a través de prensa oral y escrita. EI CEHAU aceptó la realización de los mismos mediante la firma de un acuerdo, e integró el equipo responsable con las autoras y la profesional especializada en Arqueología Lic. Belén Aguirre, a cargo de las excavaciones.

\section{ABSTRACT}

The Center for Urban and Architectural Studies, CEHAU, carries out permanently ongoing studies and research on the different cities in the region and the evolution of local architecture.

Underground structures having been found while remodelling J.B. Cabral Square in the city of Corrientes, the municipality requested that CEHAU act in order to carry out concerned studies, which was done under substantial coverage from the media. CEHAU agreed to the undertaking by signing an Agreement, and designated a team formed by the authors and a specialized Archeology professional, Lic. Belén Aguirre, to be in charge of the excavations. 


\section{OBJETIVOS}

- Reconocer los vestigios arqueológicos mediante investigación de fuentes documentales, relatos orales de los ciudadanos y excavaciones en el sitio. - Establecer la calidad y entidad de los vestigios para ser integrados a un proyecto integral de recuperación.

- Realizar recomendaciones a fin de preservar y revalorizar los diferentes elementos esenciales del hallazgo en pro de la recuperación de una etapa de la historia de los espacios públicos en la Ciudad.

\section{INTRODUCCIÓN}

A causa de la refacción que inició en agosto del corriente año la Municipalidad de la ciudad de Corrientes en la Plaza Cabral, sitio de importantes connotaciones para la comunidad correntina, el Centro de Estudios Históricos Arquitectónicos y Urbanos (CEHAU), entidad perteneciente a la UNNE con reconocimiento del CONICET y con sede en la Facultad de Arquitectura y Urbanismo, recibió por parte del Equipo Técnico encargado de las obras la solicitud de asesorar al Municipio en lo que concernía al hallazgo de restos arqueológicos; que se presumía era un pozo o posible respiradero de eventuales túneles subterráneos.

Todo lo anterior fue dado a difusión en los medios de prensa, lo que produjo una importante adhesión de la sociedad a la tarea propuesta. EI CEHAU aceptó la realización del estudio y ofreció brindar asistencia técnica a partir de él. Por su parte, la comunidad respondió en diferentes medios alentando la investigación del hallazgo y formuló variadas hipótesis sobre los vestigios.

Ante el requerimiento, se propuso a la Subsecretaría de Obras y Servicios Públicos realizar un Acuerdo de Trabajo en el marco del Convenio General ya existente entre Universidad y Municipalidad del Programa UNNE Municipios en marcha.
Términos del acuerdo. El acuerdo contempla el trabajo específico sobre el hallazgo en la Plaza Cabral con el propósito de realizar los trabajos pertinentes y necesarios a fin de reconocer el valor de lo allí estudiado; y en el caso de ser valioso, de formular recomendaciones para salvaguardar y revalorizar el hallazgo arqueológico, consistente en vestigios de un pozo calzado. Ambas partes manifiestan la voluntad de impulsar y desarrollar las actividades conjuntas que sean necesarias para lograr el fin propuesto.

El fundamento del Acuerdo de Trabajo sería lograr la solución técnica y el asesoramiento histórico adecuado a un sitio de importantes connotaciones históricas y culturales para la ciudad. Los responsables de cada entidad serían: por la Municipalidad de la Ciudad de Corrientes, la Secretaría de Planeamiento Obras y Servicios Públicos y por la Universidad Nacional del Nordeste, el Centro de Estudios Históricos, Arquitectónicos y Urbanos a través del Programa UNNE/Municipios de la Secretaría General de Extensión Universitaria. Por una parte, la Secretaría de Planeamiento proveería los recursos humanos, tecnológicos y materiales necesarios para el trabajo de campo (equipo y personal de obra y mantenimiento, maquinarias e implementos), además de ocuparse de la limpieza gruesa de cúmulos de tierra y la demarcación del sector con barandas, entre otros implementos, a fin de garantizar la seguridad del lugar. También sería responsable de solventar los gastos de papelería, impresión de fotos, etc., derivados de la investigación histórica y arqueológica. Por otra, el CEHAU recomendaría a personal técnico especializado para el trabajo de arqueología y afectaría la asistencia de investigadores especializados en el tema de Patrimonio en la Ciudad de Corrientes, para realizar el trabajo de investigación histórica a fin de llegar a un informe y de proponer las recomendaciones correspondientes. En cuanto a recursos, la Municipalidad asumiría el compromiso de contratar al profesional a cargo de las tareas de arqueología para realizar las activida- 
Con el traslado de la Catedral a su entorno, en 1874, y la construcción de la Escuela Graduada Manuel Belgrano, 1895/1897, la plaza adquiere mayor jerarquía sumando a su función comercial espontánea un rol religioso e institucional.

des propias del estudio específico, haciéndose cargo de todo lo que se refiere a proyecto, seguro personal, personal auxiliar y maquinarias para llevar a cabo las tareas de puesta en valor del solar histórico. Como resultado del acuerdo, el CEHAU se comprometía a entregar dos copias del Informe Técnico referido a dichas tareas arqueológicas, como así también de la documentación relativa a la investigación histórica, evaluación y recomendaciones de proyecto; una destinada a la Secretaría de Planeamiento y la otra, a la Universidad Nacional del Nordeste, ya que se había establecido que toda documentación resultante de las acciones conjuntas realizadas en el marco del Acta Acuerdo serían entregadas a ambas partes para su posible utilización en investigaciones, trabajos de extensión, publicaciones, aplicación, archivo o difusión, con el compromiso expreso de mencionar las fuentes y reconocer los autores actuantes en la investigación histórica y los trabajos de arqueología.

Los plazos de duración de los trabajos serían los siguientes: trabajo de arqueología: quince días intensivos (con buenas condiciones de tiempo); Trabajo de investigación y entrega de documentación: treinta días corridos a partir de la firma del acta.

\section{Desarrollo y Resultados. Breve reseña histórica} de la plaza. Siglo XIX. La actual Plaza Juan Bautista Cabral nació como un espacio suburbano con funciones de compraventa e intercambio de productos alimenticios, llamada comúnmente "piso", es decir, un espacio vacío que servía de soporte para la actividad comercial. Posteriormente funcionó como parada del trencito de trocha angosta "Ferrocarril Primer Correntino", que ingresaba a la ciudad hasta ese punto. Ello activó la circulación entre dicho espacio y la Plaza del Pisito, hoy "Libertad ", donde se encontraba la terminal ferroviaria, así como hacia la periferia, en especial con el Hipódromo. En 1886 toma su nombre definitivo con el emplazamiento, en el espacio central, de la estatua del sargento Juan Bautista Cabral, realizada por el escultor Camilo Romaironi en el Parque de Artillería de la Capital Federal a partir del fundido de cañones españoles tomados del Combate de San Lorenzo y donada luego a la ciudad de Corrientes.

Con el traslado de la Catedral a su entorno, en 1874, y la construcción de la Escuela Graduada Manuel Belgrano, 1895/1897, la plaza adquiere mayor jerarquía sumando a su función comercial espontánea un rol religioso e institucional.

En 1898 se realizan las veredas perimetrales y diagonales y se plantan los árboles por obra del ingeniero Col, convirtiéndose según los vecinos en un agradable lugar de recreo. El diseño original de esta plaza respondía a los patrones academicistas, con diagonales y líneas medias que definían un centro donde estaba ubicado el monumento al sargento Cabral sobre un magnífico pedestal, revestido en granito triturado, obra del ingeniero Juan Col. En esa oportunidad también se plantaron dos hileras de árboles de la especie tipuanatipu o tipas en el perímetro, las cuales aseguraban la sombra a los paseantes. Siglo XX. Desde principios de ese siglo la plaza formaba parte de la zona más consolidada de la ciudad y con una fuerte vocación de ser punto de enlace de transportes públicos, como el Tranway conexión Norte y Sur de la Ciudad y el ferrocarril provincial de "El Económico" hacia el Este.

Por Ordenanza 221 del 31 de mayo de 1927 el Municipio autoriza al Departamento Ejecutivo a construir cuatro pozos de agua semisurgentes con molino o motor en barrios suburbanos de la ciudad. Este dato nos permite aseverar que la modalidad de surtir agua cuando aún no había red de agua potable era a través de la ejecución de esos pozos. Aunque ya para esa fecha el área urbana del centro de la ciudad -incluida la 
Plaza Cabral- poseía provisión de agua potable. Los relatos orales señalan que la plaza, hacia la década del 30, servía de lugar de llegada de campesinos del interior, quienes la usaban como posta para ingresar a la ciudad y para realizar transacciones de alimentos y animales; y en ese sentido corroboran la existencia de un "aljibe" público que utilizaban para higienizarse. En 1930, con el desarme del Tranway y de la línea de ferrocarril de trocha angosta, la plaza igualmente funcionaba como terminal del transporte público automotor, uso que se mantuvo hasta un poco más de 1960, lo que desde luego implicaba un movimiento de personas que realizaban transbordos como también actividades comerciales ambulantes en su perímetro.

En la década del 70 fue remodelada con los criterios imperantes de la época de plaza seca con áreas funcionales delimitadas con desniveles, sectores de canteros verdes y extensas superficies de solados que intentaban aparentemente responder a la creciente demanda de flujos de circulación de la población. En esa oportunidad se lograron áreas atractivas, como el espejo de agua que albergaba el mástil o el "moderno" pedestal y la plataforma sobreelevada que rodea al sargento Cabral, ahora ya sin parterre ni cadenas.

Sin embargo, esta intervención, en la que se taló una hilera de las tipas mencionadas, no contempló las condiciones climáticas de la ciudad con largos y rigurosos veranos, lo que la llevó a no ser prácticamente transitada en su interior sino solo por sus veredas perimetrales.

Posteriormente a partir de ese abandono -como sitio propicio para el disfrute- por parte de la población, diferentes gestiones municipales tomaron a la plaza como objeto de intervenciones puntuales que, lejos de reconciliarla con la comunidad, la hicieron cada vez más inhóspita. La fuente que ya no funcionaba fue rellenada como arenero, se delimitaron sectores con barandas para patinaje, se creó una escultura que albergaba un centro de informes turísticos y se instalaron allí vendedores ambulantes que desde entonces no abandonaron el lugar, llegando a provocar una saturación completa del sitio.

Caracterización y antiguo diseño arquitectónico. La plaza cuenta desde su creación con una superficie aproximada a los mil metros cuadrados.

Su trazado original, realizado en el siglo XIX, con diagonales y líneas medias que atravesaban un espacio central donde estaba ubicado el monumento al Sargento Cabral, montado sobre escalinatas que servían de apoyo a un pedestal de líneas clásicas realizado, como se dijo, por el ingeniero Juan Col. El monumento estaba protegido con gruesas cadenas de hierro. Hacia el lado oeste se ubicaba una retreta sencilla sobreelevada que albergaba a la banda de música de la policía en los días festivos. Frente al monumento, en un sencillo mástil se izaba la bandera nacional los días patrios. (Esquema 1).

El proyecto de remodelación de la plaza en la década del 70. El proyecto de remodelación produce un cambio radical en el lugar. Abandona los lineamientos y la geometría academicista, se demuelen todos los elementos arquitectónicos como la retreta, el pedestal, las cadenas de hierro que custodiaban el monumento, así como árboles y otras especies. Solo se recupera la estatua de bronce.

Sin embargo, la estructura funcional no cambia demasiado. Se mantiene el espacio central, aunque ahora sobreelevado y ampliado, así como los cruces diagonales, aunque no tan lineales. (Imagen 1).

El gran espacio central cubierto de solado alberga en su centro un espacio rehundido definido por taludes de césped y por encima de éste se desarrolla una pasarela sobreelevada de hormigón, de 


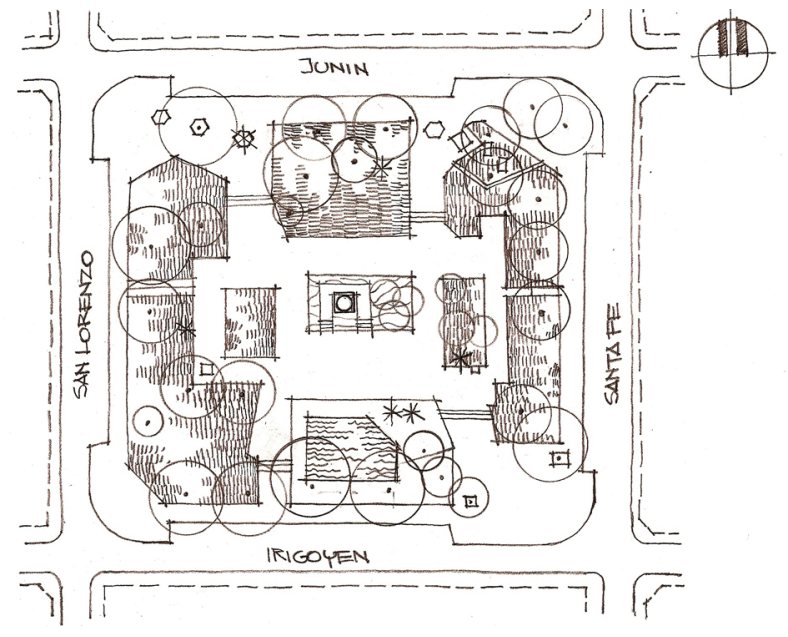

aspecto liviano, que rodea al monumento, como una especie de camino de ronda. La escultura del sargento Cabral está montada sobre un pedestal de líneas simples y puras definidas por un cilindro y un cubo.

A los lados de este espacio central se define hacia el sur y frente a la Catedral un sector institucional con mástil y originalmente un espejo de agua que luego desaparece dando lugar primero a un arenero y después a otros usos cada vez más degradados. En el lado opuesto se desarrolla una pista de patinaje. Los bordes laterales, este y oeste, están ocupados por canteros elevados que impiden la circulación en ese sentido. Posteriormente se abrió un acceso de cada lado.

El espacio tiene también la función de soporte institucional-religioso al estar ubicado frente a la Iglesia Catedral. Asimismo oficia de rótula entre la vía comercial minorista más importante de la ciudad, la peatonal Junín, y otra calle comercial de menor jerarquía, la Hipólito Irigoyen. Por lo tanto, congrega a usuarios de toda la ciudad. Además una gran cantidad de personas la utiliza como lugar de espera del transporte urbano.

(Imágenes 2 y 3).

Esto le confiere un gran dinamismo, sobre todo por el flujo constante promovido por la peatonalización de la calle Junín, que unida al sector comercial libera el punto de la bocacalle San Lorenzo con el minibanco y la oficina de informe turístico y permite usar la plaza como expansión, aunque concentra el transporte público sobre calle Santa Fe. Esta situación llevó a la ejecución de equipamiento de espera a lo largo de esta arteria.

Situación urbana. El área de influencia responde casi exclusivamente al sector comercial, ya que está comprendida por dos calles importantes so- bre las cuales se desarrolla la actividad comercial más intensa de la ciudad, así como una importante actividad turística con la presencia de dos importantes hoteles. Igualmente, no se debe dejar de considerar la actividad de la escuela primaria y la actividad religiosa ya mencionada. La vivienda está representada con el edificio Santa Fe, ubicado en Junín esquina Santa Fe, y otros dos edificios de varios pisos también sobre la calle Santa Fe.

La potencialidad del área de influencia se ve justamente en su funcionalidad netamente comercial referenciada por dos ejes comerciales que en este caso son la peatonal Junín y la calle Hipólito Irigoyen. En esta última se produce un corte, una transición en la manzana donde se encuentra la Catedral. Desde la plaza Cabral nace la calle Irigoyen, una arteria comercial paralela a la calle Junín. De uso vehicular pero con gran profusión de comercios, culmina como paseo en el encuentro con la plaza Libertad. A cien metros de ella se halla otro mercado central de productos de granja (comúnmente denominado "El Piso"), y una Feria o Mercado Paraguayo. Frente a la plaza Libertad está la Ex Estación terminal del Ferrocarril Provincial Económico.

Del estudio relativo al hallazgo arqueológico: $\mathrm{El}$ pozo. Desde hace varios años, tal vez desde que se recuperaron las antiguas estructuras de túneles y pasadizos en la ciudad de Buenos Aires como en la Ciudad de Córdoba, algunos ciudadanos alientan la hipotética existencia de túneles y conexiones ocultas en distintos sectores de la ciudad de Corrientes.

Sin dudas, este tema alimenta algunos de los mitos urbanos ya instalados en el imaginario sobre los modos de vivir, los refugios, tesoros y comunicaciones subterráneas entre grupos del vecindario colonial, por lo que ante el menor vestigio de su existencia se tejen rápidamente innumerables hipótesis y suposiciones. 
2. Principio de la década de 2000 , se aprecia en el sector tomado hacia la Catedral parte de la ocupación de los vendedores informales asentados en forma permanente en la Plaza.

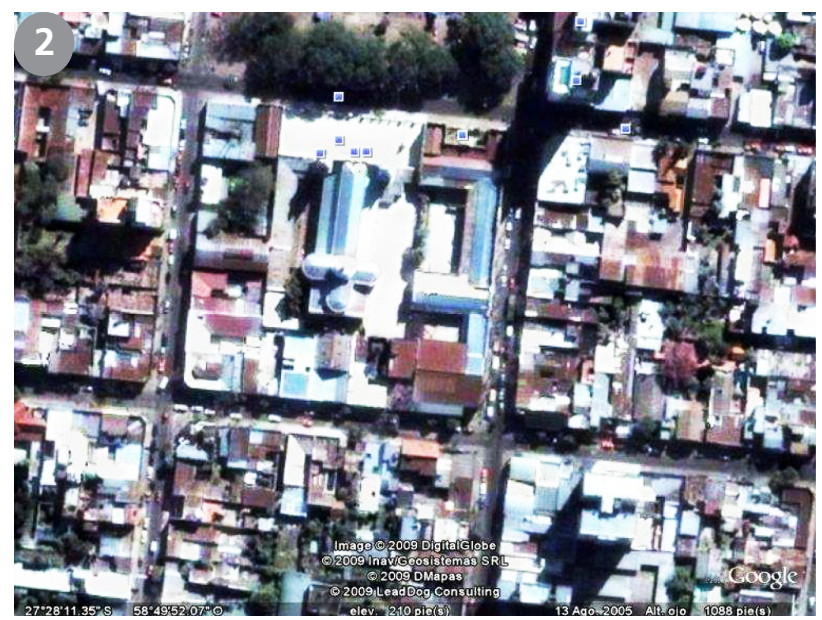

La situación generada por el hallazgo invadió los medios de prensa y los del ciberespacio; twitter, Facebook. A pesar de que la plaza está en medio de un espacio público sin relación con el medio físico propio del periodo colonial -la formación de la plaza data del periodo independiente en el siglo XIX-, la población ansiaba descubrir una conexión de túneles.

Desde el momento en que el CEHAU fue convocado para visitar el lugar y establecer las medidas para su estudio y reconocimiento, se estableció que tenía la escala y características de consolidación (pared circular en ladrillo cocido, anillo de ladrillo y argamasa de mezcla común en el borde superior) coincidente con las de un pozo de agua. Se planteó así la hipótesis de un pozo para abastecimiento de agua de uso de la plaza. En ese sentido debía realizarse el trabajo arqueológico y verificación física hasta un nivel de profundidad mayor, ya que llegaba aproximadamente a unos cuatro metros de profundidad.

A su vez se inició la compulsa de documentación y fuentes diversas para la verificación de esta hipótesis, lo que se hacía cada vez más imperioso teniendo en cuenta que la comunidad se expresaba argumentando la existencia de túneles. (Fotos 1 Y 2).

Según su definición, un pozo es "un agujero o excavación vertical efectuada mediante una perforación en la tierra, hasta una profundidad suficiente para alcanzar lo que se busca, en este caso en estudio: la reserva de agua subterránea del nivel freático. Generalmente de forma cilíndrica, se suele tomar la precaución de asegurar sus paredes con ladrillo, piedra, cemento o madera, para evitar su deterioro y derrumbe".

Los pozos tradicionales para recoger agua suelen emplazarse en el entorno de las casas, bien en el patio de la vivienda o en la zona común vecinal (plaza, encrucijada de calles), siempre y cuando se
3. Imagen aérea, fines de 2010. Durante 2011 peatonalización sobre Junín e incorporación de lugares de espera techados, buena iluminación; diversos senderos de conexión este/oeste.

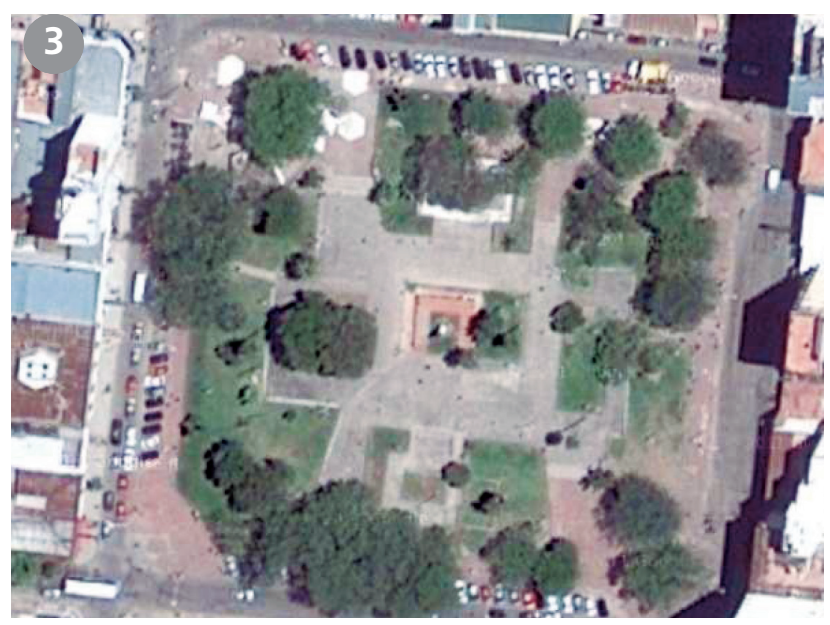

halle agua a un nivel moderadamente profundo. Por seguridad y utilidad, el pozo se rodea a nivel de superficie con un brocal, a modo de pretil o parapeto, sobre el que se instala una polea o un cigüeño para subir el cubo que contiene el agua extraída. También se le suele colocar una tapadera para evitar que caiga suciedad en el interior.

En las poblaciones donde, por filtración de aguas residuales, el nivel freático puede estar contaminado y el agua del pozo ya no se puede beber, puede seguir utilizándose para labores de limpieza y riego. En la antigüedad y en el Tercer Mundo rural, cuando el pozo no es potable se va a la fuente más cercana.

Si bien los restos más antiguos de un pozo datan del siglo XII a.C. en Persia, en lo que respecta a la influencia en Latinoamérica, los que más han desarrollado estas perforaciones han sido los árabes, quienes a través de su influencia en la arquitectura mudéjar española, han dejado su impronta en América. (Imagen 4).

Investigación del Estado Dominial y catastral de la manzana de la Plaza. En relación con la búsqueda de información oral, se realizaron diferentes entrevistas a vecinos del lugar como a antiguos empleados municipales y a otros vecinos que se presentaron espontáneamente. Entre ellos surgió la visita de una antigua pobladora que argumentó con antecedentes fundados la evidencia de propiedad de la manzana de la plaza, antes de la decisión municipal de ser destinada a espacio público.

En la documentación dominial que nos acercó se lee que los antiguos dueños - familia León y sucesores Solari - poseían lotes urbanos en la manzana de la plaza. Este documento permite determinar que el Estado adquiere parte de la propiedad en 1848 para "despejar "el sitio de la Plaza que denomina 
4. El pozo. a- Imagen hacia su interior b- Imagen del borde superficial del pozo.

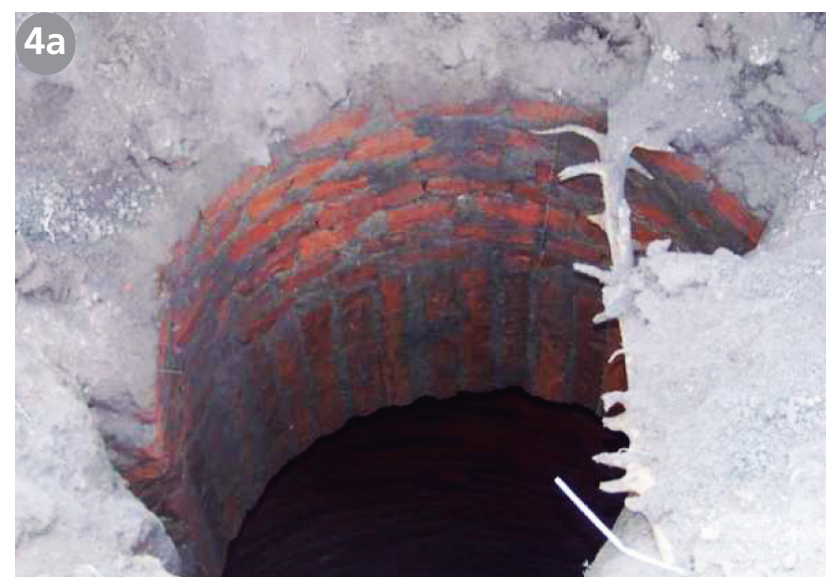

partir de ese momento como San Juan Bautista en honor al patrono de la ciudad (nombre que será cambiado a fines del siglo XIX por el de "Juan Bautista Cabral" con la instalación de su monumento). El documento en cuestión es objeto de saneamiento como escritura a favor de los herederos justamente en el año 1887, lo que lleva a presumir que obedece a la necesidad de sanear la situación ante la inminencia de la instalación del Monumento.

A pesar de lo relatado por la Sra. Marta Solari Vedoya, no se pudo constatar que hubiera construcciones en dicho solar (sector oeste de la plaza en la esquina de Junín y calle Entre Ríos, actual San Lorenzo), aunque deja la duda de la existencia de otros vestigios anteriores a la plaza misma. En el estudio de imágenes fotográficas tampoco se observan rastros de edificios, sino por el contrario un gran descampado (Fotos 4 y 5).

Investigación fotográfica. Debido a la necesidad de verificar la existencia del pozo en cuestión y en función de no haber podido determinar a partir de las fuentes documentales escritas referencias específicas de la construcción del pozo, se determinó como fundamental explorar el material fotográfico. (Imágenes 5, 6, 7 y 8).

\section{INFORME TÉCNICO - ARQUEOLÓGICO}

La licenciada Belén Aguirre realizó las excavaciones del sitio verificando la hipótesis inicial del CEHAU- en contrario con lo que la comunidad deseaba encontrar y que algunas leyendas urbanas contribuían a alimentar: la existencia de túneles secretos en el subsuelo de la plaza.

Se determinó entonces que los hallazgos se condecían con un pozo de tipo semisurgente, posiblemente para provisión de agua a este espacio pú-

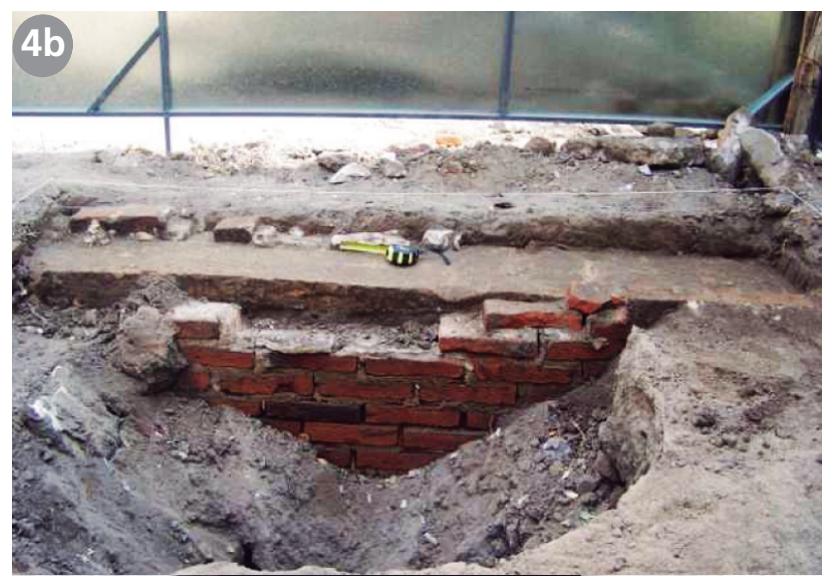

blico. El mismo, con forma circular, que pudo ser estudiado hasta unos cinco metros de profundidad aproximadamente. Según lo observado, el pozo se encuentra calzado en forma anillar con hiladas de ladrillo cocido asentado en suelo-cemento con un anillo reforzado en su parte superior hasta un poco más de cinco metros, profundidad hasta la que se realizó el estudio.

Durante su existencia tuvo al menos dos etapas muy marcadas: una de uso de pozo de agua que dataría de fines de siglo XIX por la lectura de los componentes y la necesidad de riego de la forestación emprendida; y otra, de intento de relleno y tapado posiblemente en la última remodelación más importante, que data de 1972.

\section{CONCLUSIONES Y REFLEXIONES FINALES}

En relación con el hallazgo en sí, se concluye que el pozo encontrado se corresponde con un pozo de provisión de agua, tal como lo determinan las obras de salubridad por parte del Municipio y confirmando lo que algunas de las personas relataron sobre el aseo que realizaban los eventuales usuarios de la plaza.

Por esta razón, se considera que tiene atributos suficientes para ser revalorizado como protagonista importante de parte de la memoria que los ciudadanos poseen sobre un periodo en que no existía aún la provisión de agua potable ni red alguna. Resta actualmente la elaboración de recomendaciones y propuestas que tener en cuenta para la incorporación al diseño que se encuentra en ejecución.

Con referencia a la tramitación administrativa de firma del acuerdo de trabajo para la asistencia técnica entre la UNNE y el Municipio de la Ciudad de Corrientes, como ha ocurrido en algunas otras ac- 
5. Acto de inauguración 1887 del monumento a Juan. B. Cabral. 6. 1887. Se coloca el Monumento a Cabral con su basamento en el centro de la Plaza. Nótese que la Iglesia del Rosario, desde 1874 Catedral, es la única construcción sobre la actual calle $\mathrm{H}$ Yrigoyen. (1 . er basamento con pedestal de un cuerpo) 7.1897. El Ing. Col realiza una revalorización del pedestal del Monumento en líneas historicistas y en mayor altura ( $2 .^{\circ}$ basamento, ahora de dos cuerpos).
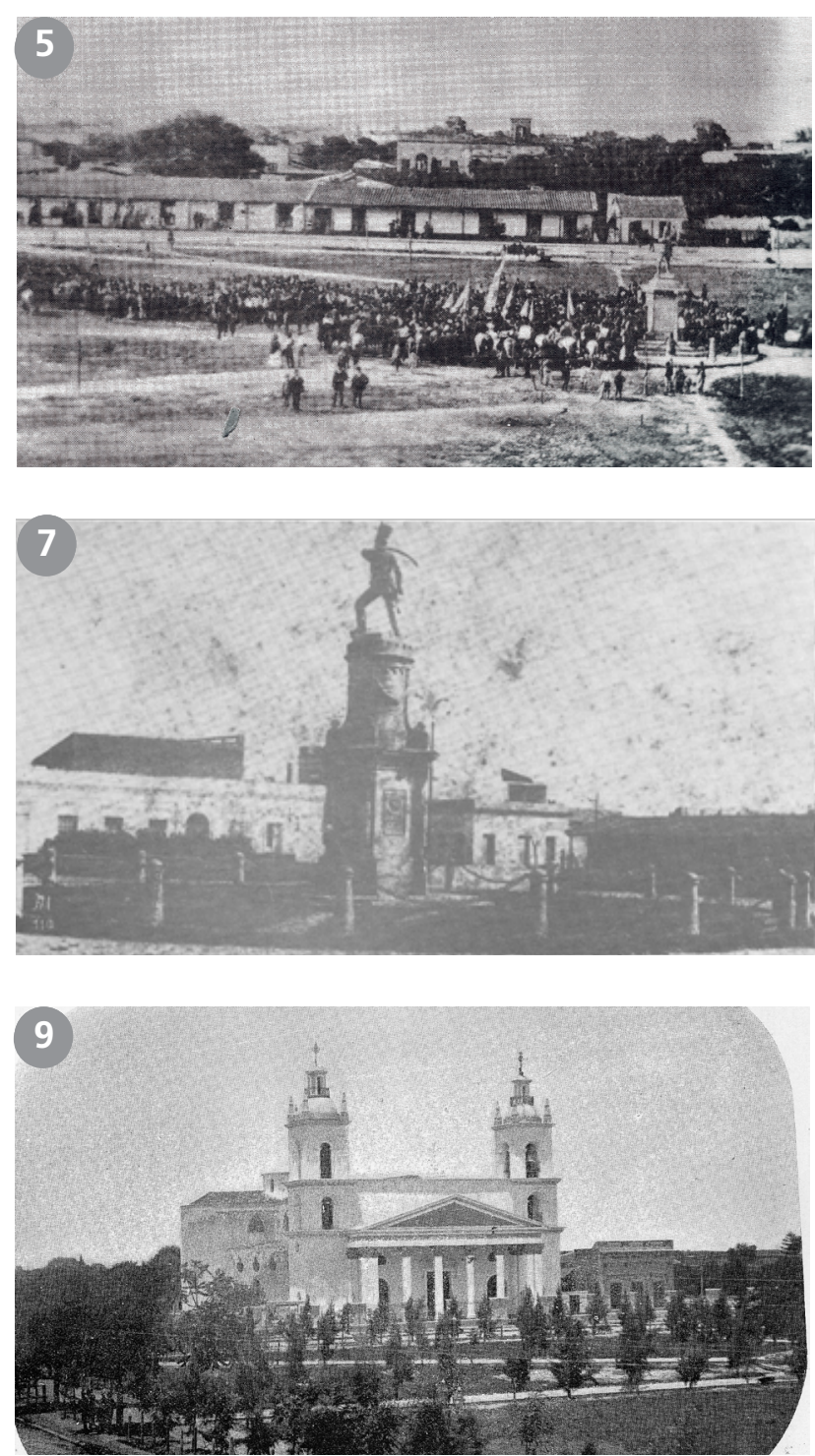

tividades, los trámites correspondientes se tornan engorrosos por los diferentes circuitos que deben transitar y muchas de las veces, como en este caso, el acuerdo continúa en tramitaciones aun cuando el estudio ya se encuentra en sus instancias finales. Igual se sostiene que desde todo punto de vista el trabajo interdisciplinarioy abierto a la participación de los vecinos es esencial para el reconocimiento de los sitios históricos. Los miembros del CEHAU consideran que gran parte de la estrategia de reconoci-
8. 1897. Mes de febrero. Inauguración de la Escuela Belgrano, proyecto del Ing. Juan Col.

9. 1900. Imagen de la plaza con un trazado simple de diagonales y el arbolado que se observa como de reciente formación. Nota: Se puede observar un blanco en el césped en el lugar donde se encuentra el vestigio.

10.1909. Se modifica el basamento ( $2^{\circ}$ basamento) y se complementa con una retreta. Obsérvese que ya la forestación es profusa y posee una red de iluminación eléctrica. Puede verse a personal de la plaza regando el césped con manguera, lo que indica ya una red de agua; el pozo podría mantenerse solo como reservorio de agua. Este aspecto se mantiene hasta postales de la década de 1960.
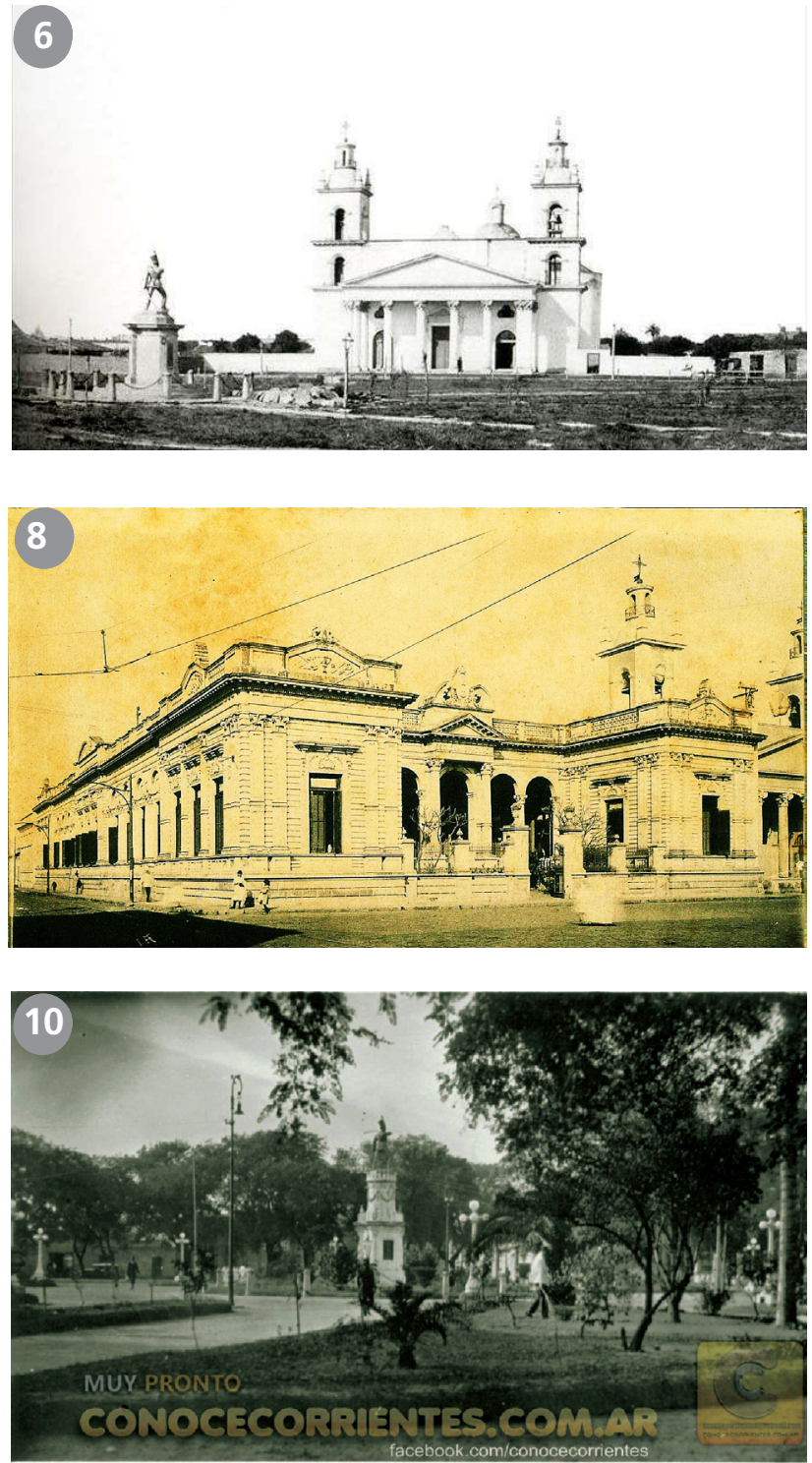

miento de una comunidad con su patrimonio urbano se basa en la amplitud y participación vecinal al margen del estudio técnico que se pueda desarroIlar como especialistas o arquitectos historiadores.

El trabajo de arqueología urbana fue parte de las tareas de seguimiento y evaluación por parte del CEHAU e implicó una serie de reuniones de trabajo tanto para ir estableciendo la lectura de las etapas de la excavación como para la comprensión de 
11. 1937. Imagen desde la retreta hacia el monumento. ( $2^{\circ}$ basamento).

12. Década de 1950. Sector de la plaza con las paradas como punto de tras bordo, del transporte público. (Colectivos urbanos y colectivos de media distancia).

13. Década de 1960 aproximadamente (3. er basamento) Imagen postal, todavía con la retreta. Se conoce la existencia de una casilla en la zona del hallazgo que podría haber servido para guardar los implementos de mantenimiento de la plaza.
14. Década de 1970. Imagen postal de la intervención del Intendente Torres con reforma total de la plaza (4. ${ }^{\circ}$ basamento) y elevación de cota al nivel actual, instancia en que se cubre el pozo y el IGM.

15. Década de 1989/90. Intervención de la intendenta Pando. 16. Imágenes últimas, antes de la nueva intervención de 2012.
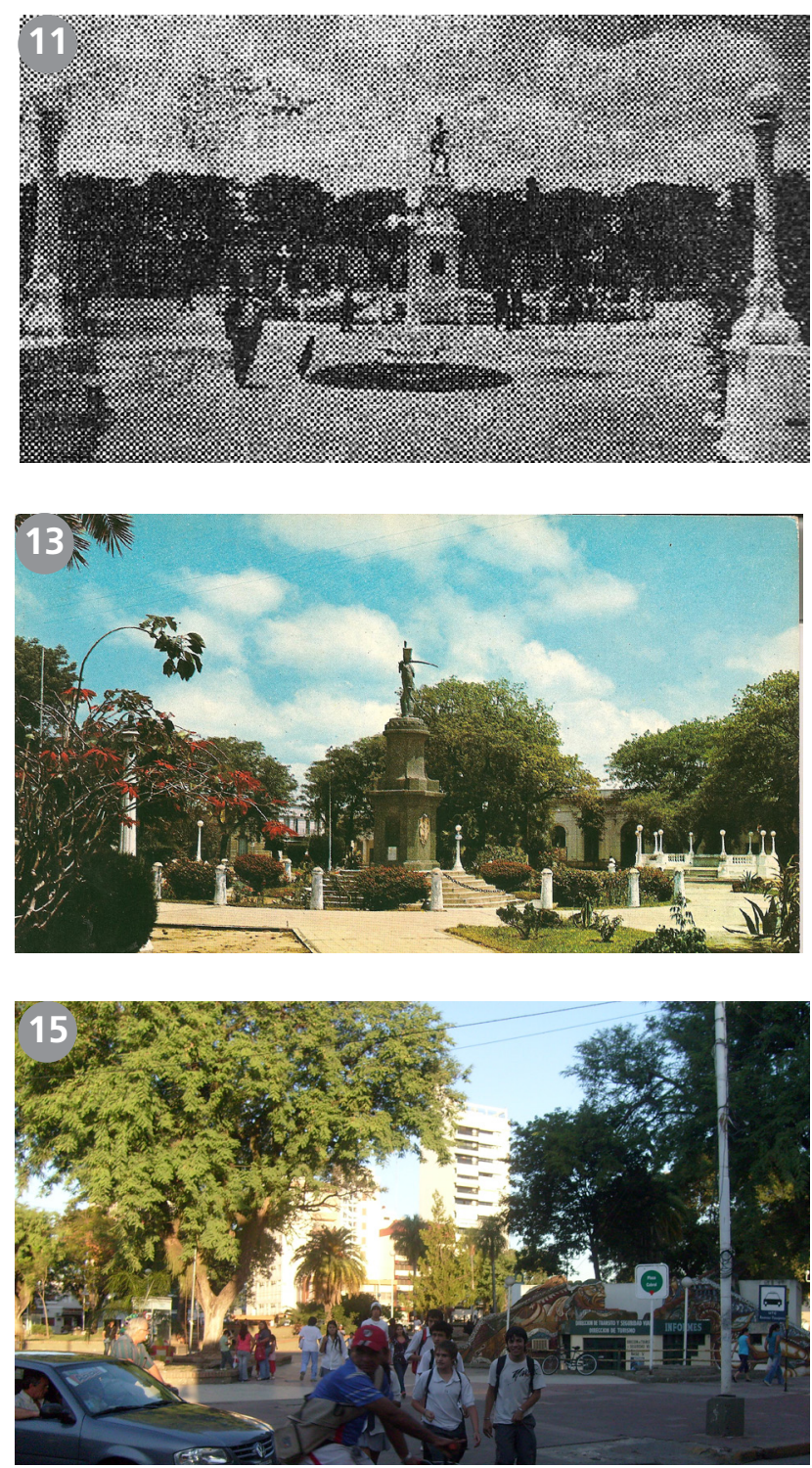

los mismos a la luz de las fuentes documentales encontradas. Así también fue necesaria la verificación y contraste de la información oral provista por los ciudadanos, que en este caso en particular ha sido muy abundante aunque sin modo concreto de probarla fehacientemente, lo que obligó a una lectura pormenorizada y objetiva de los datos históricos contrastando tal información, en los casos que fuese pertinente, con los relatos recogidos.

Por lo expuesto, se espera que esta experiencia
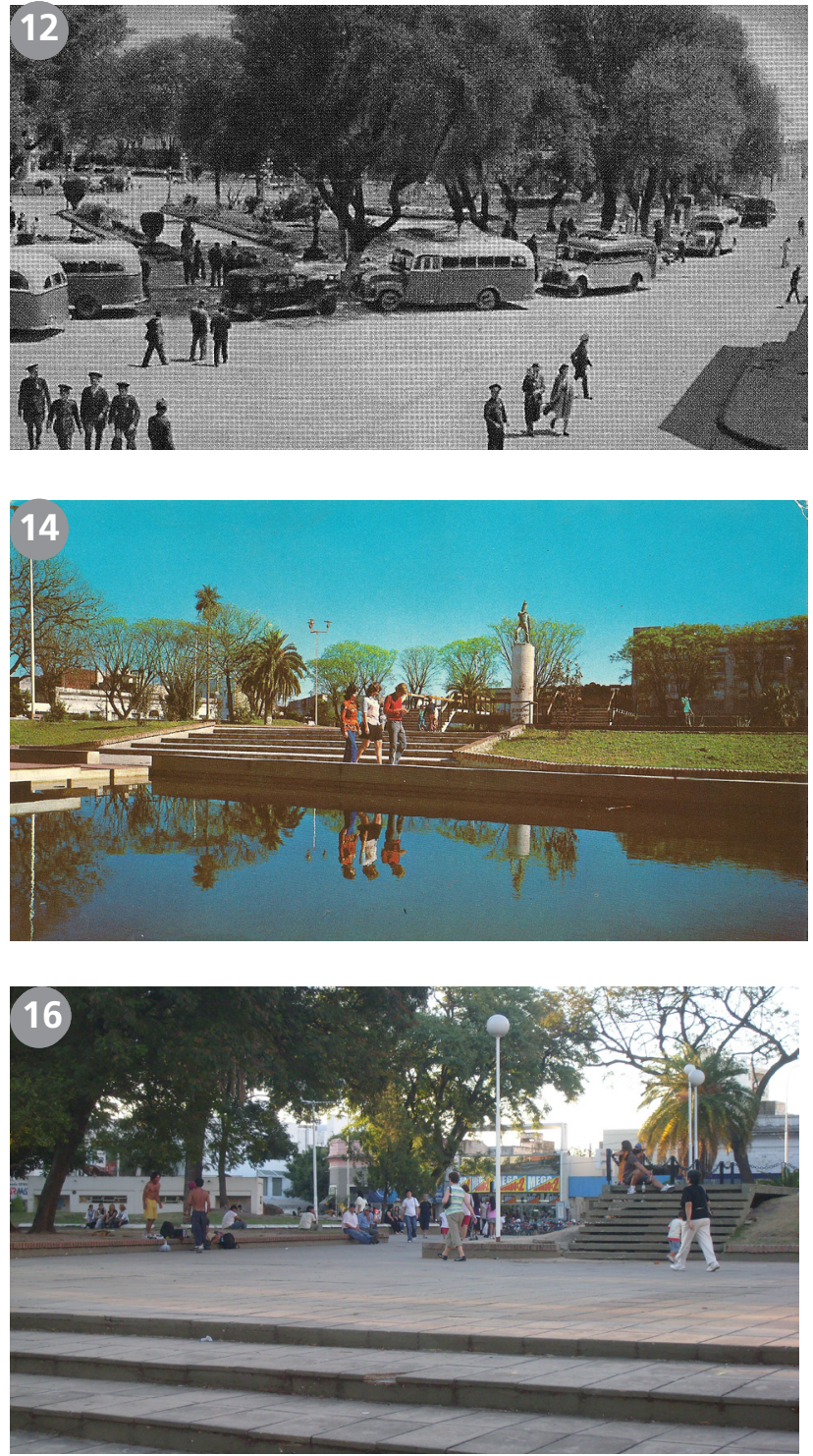

permita enriquecer el trabajo de la universidad y los municipios contribuyendo a la formación de los ciudadanos y al reconocimiento del sitio patrimonial con el propósito de vincularlos con el pasado de la ciudad en la que residen, para que puedan incluso llegar a ser difusores del conocer, proteger y mantener viva esa historia; de forma tal de asegurar la transmisión de la memoria urbana a través de las distintas generaciones. 


\section{BIBLIOGRAFÍA}

- Ambrosetti, Juan. (1893). Viaje al Iguazú. Buenos Aires.

- Coni, Emilio. (1898). Higiene aplicada de la Provincia de Corrientes. Publicación Oficial. Buenos Aires.

- De Monte Dirce, Paola y Díaz, Omar Enrique. (2011). "La industria ladrillera actividad milenaria, millonaria y postergada". En: $2^{\circ}$ edición Concurso Bicentenario de la Patria. Premios Bialet Massé. Ministerio de Trabajo de la Provincia de Buenos Aires. Buenos Aires.

- Figuerero, Manuel V.(1929).Lecciones de historiografía. Corrientes.

- Gómez, Hernán. (1944)Historia de la Provincia de Corrientes. Ed. Corrientes. Corrientes.

- Gómez, Hernán. (1942) Monumentos y lugares históricos de Corrientes. Buenos Aires.

- Gutiérrez, Ramón, Sánchez Negrette, Ángela. (1988) Evolución Urbana y Arquitectónica de la Ciudad de Corrientes. Tomo 2. IIHAU. Buenos Aires.

- Lámperez y Romea, Vicente. (1922). Arquitectura Civil Española de los siglos I al XVIII. Madrid.

- Rivera, Alberto. (1980). "Una descripción inédita de Manuel F. Mantilla de la Ciudad de Corrientes, año 1895". Folia Histórica del Nordeste Nº 4- IGHI. Resistencia, Chaco.

- Romero, José L. (1976).Latinoamérica, las Ciudades y las Ideas. Siglo XXI. Argentinos Editores. Buenos Aires.

- Sánchez Negrette, Angela: (1999) "La imagen de la ciudad y la Generación del '80 en Corrientes". Anales de la Junta de Historia de la Provincia de Corrientes N. ${ }^{\circ}$ 1. Corrientes

- Sánchez Negrette,Angela;Valenzuela Ma. V.; Benavidez Casal,A. (2010): "Paisaje, identidad y cambio en la Plaza J. B. Cabral, plaza histórica de la ciudad de Corrientes". CEHAU-UNNE/CONICET. En: ${ }^{\circ}$ Seminario Las Calles y El Espacio Público. Pensamiento, diseño, gestión y realidad. Resistencia, Chaco.

- Serrano, Benjamín. (1910). Guía de la Provincia de Corrientes. Heinecke Editora. Corrientes.

- Valenzuela, M. Victoria (2008), Paisaje Natural Y Cultural De La Ciudad De Corrientes, CEHAU-UNNE. Corrientes.

- Diario "La Reacción" (1901).Notas editoriales. Archivo Gral. de la Prov. de Corrientes.

\section{FUENTES}

- Registro Oficial de la Provincia de Corrientes. Años 1853 a 1877. Archivo Gral. de la Prov. de Corrientes.

- Digesto Municipal de la Ciudad de Corrientes. Municipalidad de la Ciudad de Corrientes. 